Bull. Korean Math. Soc. 50 (2013), No. 2, pp. 375-388

http://dx.doi.org/10.4134/BKMS.2013.50.2.375

\title{
WEAK AND STRONG CONVERGENCE THEOREMS FOR A SYSTEM OF MIXED EQUILIBRIUM PROBLEMS AND A NONEXPANSIVE MAPPING IN HILBERT SPACES
}

\author{
Somyot Plubtieng and Kamonrat Sombut
}

\begin{abstract}
In this paper, we introduce an iterative sequence for finding solution of a system of mixed equilibrium problems and the set of fixed points of a nonexpansive mapping in Hilbert spaces. Then, the weak and strong convergence theorems are proved under some parameters controlling conditions. Moreover, we apply our result to fixed point problems, system of equilibrium problems, general system of variational inequalities, mixed equilibrium problem, equilibrium problem and variational inequality.
\end{abstract}

\section{Introduction}

Let $C$ be a nonempty closed convex subset of a real Hilbert space $H$. Recall that a mapping $f: C \rightarrow C$ is called contractive if there exists a constant $\alpha \in(0,1)$ such that $\|f(x)-f(y)\| \leq \alpha\|x-y\|$ for all $x, y \in C$. A mapping $T: C \rightarrow C$ is said to be nonexpansive if $\|T x-T y\| \leq\|x-y\|$ for all $x, y \in C$. Denote the set of fixed points of $T$ by $F(T)$. Fixed point iterations process for nonexpansive mappings in Banach spaces including Mann and Ishikawa iterations process have been studied extensively by many authors to solve the nonlinear operator equations. In 1953, W. R. Mann [14] introduced Mann iterative process defined by

$$
x_{n+1}=\left(1-\alpha_{n}\right) x_{n}+\alpha_{n} T x_{n},
$$

where $\alpha_{n} \in[0,1]$ and satisfies the assumptions $\lim _{n \rightarrow \infty} \alpha_{n}=0, \sum_{n=1}^{\infty} \alpha_{n}=\infty$ and proved the convergence of $\left\{x_{n}\right\}$ to a point $y$ implies that $T y=y$.

Let $\varphi: C \rightarrow \mathbb{R}$ be a real-valued function and $F: C \times C \rightarrow \mathbb{R}$ be an equilibrium bifunction, that is, $F(u, u)=0$ for each $u \in C$. The mixed equilibrium problem is to find $x^{*} \in C$ such that

$$
F\left(x^{*}, y\right)+\varphi(y)-\varphi\left(x^{*}\right) \geq 0 \text { for all } y \in C .
$$

Received June 7, 2010; Revised December 13, 2011.

2010 Mathematics Subject Classification. 49J30, 49J53, 47H09, 47H10.

Key words and phrases. nonexpansive mapping, system of mixed equilibrium problems, fixed point, weak convergence, strong convergence. 
Denote the set of solution of (1.2) by $\operatorname{MEP}(F, \varphi)$.

In particular, if $\varphi=0$, this problem reduces to the equilibrium problem, which is to find $x^{*} \in C$ such that

$$
F\left(x^{*}, y\right) \geq 0 \text { for all } y \in C .
$$

The set of solutions of $(1.3)$ is denoted by $E P(F)$. Numerous problems in physics, optimization, and economics reduce to find a solution of (1.3). The mixed equilibrium problems include fixed point problems, optimization problems, variational inequality problems, Nash equilibrium problems, and the equilibrium problems as special cases (see, e.g., [2, 3, 5, 6, 7, 8, 9, 13, 15, 20, 21, $22,27,31,32])$.

Let $F_{1}, F_{2}: C \times C \rightarrow \mathbb{R}$ be two monotone bifunctions and $\lambda, \mu>0$ are two constants. In 2009, Moudafi [16] considered the following problem for finding $\left(x^{*}, y^{*}\right) \in C \times C$ such that finding $\left(x^{*}, y^{*}\right) \in C \times C$ such that

$$
\left\{\begin{array}{l}
F_{1}\left(x^{*}, z\right)+\frac{1}{\lambda}\left\langle y^{*}-x^{*}, x^{*}-z\right\rangle \geq 0, \quad \forall z \in C, \\
F_{2}\left(y^{*}, z\right)+\frac{1}{\lambda}\left\langle x^{*}-y^{*}, y^{*}-z\right\rangle \geq 0, \quad \forall z \in C .
\end{array}\right.
$$

Using the following alternating equilibrium algorithm: $\left(x_{0}, y_{0}\right) \in H \times H$ given, $\left\{x_{k}\right\}$ and $\left\{y_{k}\right\}$ be sequences in $H$ defined by

$$
\left\{\begin{array}{l}
\lambda F_{1}\left(x_{k+1}, z\right)+\left\langle y_{k}-x_{k+1}, x_{k+1}-z\right\rangle \geq 0, \quad \forall z \in C, \\
\lambda F_{2}\left(y_{k+1}, z\right)+\left\langle x_{k+1}-y_{k+1}, y_{k+1}-z\right\rangle \geq 0, \quad \forall z \in C .
\end{array}\right.
$$

Moudafi proved that the sequence $\left(x_{k}, y_{k}\right)$ weakly converges to a solution of the problem (1.4). Further, if we add up the requirement that $x^{*}=y^{*}$, then problem (1.4) reduce to the equilibrium problem (1.3).

In this paper, we consider the following problem for finding $\left(x^{*}, y^{*}\right) \in C \times C$ such that

$$
\left\{\begin{array}{l}
F_{1}\left(x^{*}, z\right)+\varphi(z)-\varphi\left(x^{*}\right)+\frac{1}{\lambda}\left\langle y^{*}-x^{*}, x^{*}-z\right\rangle \geq 0, \quad \forall z \in C, \\
F_{2}\left(y^{*}, z\right)+\varphi(z)-\varphi\left(y^{*}\right)+\frac{1}{\mu}\left\langle x^{*}-y^{*}, y^{*}-z\right\rangle \geq 0, \quad \forall z \in C,
\end{array}\right.
$$

which is called a system of mixed equilibrium problems. In particular, if $\lambda=\mu$, then problem (1.6) reduce to finding $\left(x^{*}, y^{*}\right) \in C \times C$ such that

$$
\left\{\begin{array}{l}
F_{1}\left(x^{*}, z\right)+\varphi(z)-\varphi\left(x^{*}\right)+\frac{1}{\lambda}\left\langle y^{*}-x^{*}, x^{*}-z\right\rangle \geq 0, \quad \forall z \in C, \\
F_{2}\left(y^{*}, z\right)+\varphi(z)-\varphi\left(y^{*}\right)+\frac{1}{\lambda}\left\langle x^{*}-y^{*}, y^{*}-z\right\rangle \geq 0, \quad \forall z \in C .
\end{array}\right.
$$

If $\varphi=0$ and $\lambda=\mu$, then the problem (1.6) reduce to problems (1.7).

The system of nonlinear variational inequalities close to these introduce by Verma [28] are also a special case: by taking $\varphi=0, F_{1}(x, y)=\langle A(x), y-x\rangle$ and $F_{2}(x, y)=\langle B(x), y-x\rangle$, where $A, B: C \rightarrow H$ are two nonlinear mappings. In this case, we can reformulate problem (1.7) to finding $\left(x^{*}, y^{*}\right) \in C \times C$ such that

$$
\left\{\begin{array}{l}
\left\langle\lambda A\left(x^{*}\right)+x^{*}-y^{*}, z-x^{*}\right\rangle \geq 0, \quad \forall z \in C, \\
\left\langle\mu B\left(y^{*}\right)+y^{*}-x^{*}, z-y^{*}\right\rangle \geq 0, \quad \forall z \in C,
\end{array}\right.
$$


which is called a general system of variational inequalities, where $\lambda>0$ and $\mu>0$ are two constants. Moreover, if we add up the requirement that $x^{*}=y^{*}$, then problem (1.8) reduce to the classical variational inequality $V I(A, C)$.

In this paper, we organize as follows. In Section 2 , we present some basic concepts and useful lemmas for proving the convergence results of this paper. In Section 3, we introduce two iterative sequences (3.1) and (3.5). Moreover, we prove weak and strong convergence theorems for finding solution of a system of mixed equilibrium problems and the set of fixed points of a nonexpansive mapping in Hilbert spaces. Finally, we apply our result to fixed point problems, system of equilibrium problems, general system of variational inequalities, mixed equilibrium problem, equilibrium problem and variational inequality.

\section{Preliminaries}

Let $H$ be a real Hilbert space with inner product $\langle\cdot, \cdot\rangle$ and norm $\|\cdot\|$, and let $C$ be a closed convex subset of $H$. For every point $x \in H$, there exists a unique nearest point in $C$, denote by $P_{C} x$, such that

$$
\left\|x-P_{C} x\right\| \leq\|x-y\| \text { for all } y \in C .
$$

$P_{C}$ is called the metric projection of $H$ onto $C$. It is well-known that $P_{C}$ is a nonexpansive mapping of $H$ onto $C$ and satisfies

$$
\left\langle x-y, P_{C} x-P_{C} y\right\rangle \geq\left\|P_{C} x-P_{C} y\right\|^{2}
$$

for all $x, y \in H$. Moreover, $P_{C} x$ is characterized by the following properties: $P_{C} x \in C$ and

$$
\begin{gathered}
\left\langle x-P_{C} x, y-P_{C} y\right\rangle \leq 0 \\
\|x-y\|^{2} \geq\left\|x-P_{C} x\right\|^{2}+\left\|y-P_{C} y\right\|^{2}
\end{gathered}
$$

for all $x \in H, y \in C$. Further, for all $x \in H$ and $y \in C, y=P_{C} x$ if and only if $\langle x-y, y-z\rangle \geq 0, \forall z \in C$.

A space $X$ is said to satisfy Opial's condition if for each sequence $\left\{x_{n}\right\}_{n=1}^{\infty}$ in $X$ which converges weakly to point $x \in X$, we have

$$
\liminf _{n \rightarrow \infty}\left\|x_{n}-x\right\|<\liminf _{n \rightarrow \infty}\left\|x_{n}-y\right\|, \forall y \in X, y \neq x
$$

and

$$
\limsup _{n \rightarrow \infty}\left\|x_{n}-x\right\|<\limsup _{n \rightarrow \infty}\left\|x_{n}-y\right\|, \forall y \in X, y \neq x
$$

Next, we collects some lemmas which will be use in the next section.

Lemma $2.1([18])$. Let $(E,\langle\cdot, \cdot\rangle)$ be an inner product space. Then for all $x, y, z \in E$ and $\alpha, \beta, \gamma \in[0,1]$ with $\alpha+\beta+\gamma=1$, we have

$\|\alpha x+\beta y+\gamma z\|^{2}=\alpha\|x\|^{2}+\beta\|y\|^{2}+\gamma\|z\|^{2}-\alpha \beta\|x-y\|^{2}-\alpha \gamma\|x-z\|^{2}-\beta \gamma\|y-z\|^{2}$. 
Lemma 2.2 ([12]). Let $H$ be a Hilbert space, $C$ a closed convex subset of $H$, and $T: C \rightarrow C$ a nonexpansive mapping with $F(T) \neq \emptyset$. If $\left\{x_{n}\right\}$ is a sequence in $C$ weakly converging to $x \in C$ and if $\left\{(I-T) x_{n}\right\}$ converges strongly to $y$, then $(I-T) x=y$.

Lemma $2.3([26])$. Let $C$ be a closed convex subset of a real Hilbert space $H$ and let $\left\{x_{n}\right\}$ be a sequence in $H$. Suppose that for all $u \in C$,

$$
\left\|x_{n+1}-u\right\| \leq\left\|x_{n}-u\right\|
$$

for every $n=0,1,2, \ldots$ Then, $\left\{P_{C} x_{n}\right\}$ converges strongly to some $z \in C$.

Lemma 2.4 ([29]). Assume $\left\{a_{n}\right\}$ is a sequence of nonnegative real numbers such that

$$
a_{n+1} \leq\left(1-\alpha_{n}\right) a_{n}+\delta_{n}, n \geq 0,
$$

where $\left\{\alpha_{n}\right\}$ is a sequence in $(0,1)$ and $\left\{\delta_{n}\right\}$ is a sequence in $\mathbb{R}$ such that

(1) $\sum_{n=1}^{\infty} \alpha_{n}=\infty$,

(2) $\limsup _{n \rightarrow \infty} \frac{\delta_{n}}{\alpha_{n}} \leq 0$ or $\sum_{n=1}^{\infty}\left|\delta_{n}\right|<\infty$.

Then $\lim _{n \rightarrow \infty} a_{n}=0$.

For solving the mixed equilibrium problems for an equilibrium bifunction $F: C \times C \rightarrow \mathbb{R}$, let us assume that $F$ satisfies the following conditions:

(A1) $F(x, x)=0$ for all $x \in C$;

(A2) $F$ is monotone, that is, $F(x, y)+F(y, x) \leq 0$ for all $x, y \in C$;

(A3) for each $x, y, z \in C, \lim _{t \rightarrow 0} F(t z+(1-t) x, y) \leq F(x, y)$;

(A4) for each $x \in C, y \mapsto F(x, y)$ is convex and lower semicontinuous;

(B1) for each $x \in H$ and $r>0$, there exists a bounded subset $D_{x} \subseteq C$ and $y_{x} \in C$ such that for any $z \in C \backslash D_{x}$,

$$
F\left(z, y_{x}\right)+\varphi\left(y_{x}\right)-\varphi(z)+\frac{1}{r}\left\langle y_{x}-z, z-x\right\rangle<0
$$

(B2) $C$ is a bounded set.

The following lemmas appears implicitly in [3] and [11].

Lemma $2.5([3])$. Let $C$ be a nonempty closed convex subset of $H$ and let $F$ be a bifunction of $C \times C$ into $\mathbb{R}$ satisfying (A1)-(A4). Let $r>0$ and $x \in H$. Then, there exists $z \in C$ such that

$$
F(z, y)+\frac{1}{r}\langle y-z, z-x\rangle \geq 0 \text { for all } y \in C .
$$

Lemma 2.6 ([11]). Assume that $F: C \times C \rightarrow \mathbb{R}$ satisfies (A1)-(A4). For $r>0$ and $x \in H$, define a mapping $T_{r}: H \rightarrow C$ as follows:

$$
T_{r}(x)=\left\{z \in C: F(z, y)+\frac{1}{r}\langle y-z, z-x\rangle \geq 0, \forall y \in C\right\}
$$

for all $z \in H$. Then, the following hold:

(1) $T_{r}$ is single-valued; 
(2) $T_{r}$ is firmly nonexpansive, i.e., for any $x, y \in H$,

$$
\left\|T_{r} x-T_{r} y\right\|^{2} \leq\left\langle T_{r} x-T_{r} y, x-y\right\rangle
$$

(3) $F\left(T_{r}\right)=E P(F)$;

(4) $E P(F)$ is closed and convex.

By a similar argument as in the proof of Lemma 2.3 in [19], we have the following result.

Lemma 2.7 ([19]). Let $C$ be a nonempty closed convex subset of a real Hilbert space $H$. Let $F: C \times C \rightarrow \mathbb{R}$ be an equilibrium bifunction satisfying (A1)-(A4) and let $\varphi: C \rightarrow \mathbb{R}$ be a lower semicontinuous and convex functional. For $r>0$ and $x \in H$, define a mapping $S_{r}(x): H \rightarrow C$ as follows.

$S_{r}(x)=\left\{y \in C: F(y, z)+\varphi(z)-\varphi(y)+\frac{1}{r}\langle y-x, z-y\rangle \geq 0, \forall z \in C\right\} \forall x \in H$.

Then, the following results hold:

(i) For each $x \in H, S_{r}(x) \neq \emptyset$;

(ii) $S_{r}$ is single-valued;

(iii) $S_{r}$ is firmly nonexpansive, i.e., for any $x, y \in H$

$$
\left\|S_{r}(x)-S_{r}(y)\right\|^{2} \leq\left\langle S_{r}(x)-S_{r}(y), x-y\right\rangle ;
$$

(iv) $F\left(S_{r}\right)=\operatorname{MEF}(F, \varphi)$;

(v) $\operatorname{MEF}(F, \varphi)$ is closed and convex.

Lemma 2.8. Let $C$ be a closed convex subset of a real Hilbert space $H$. Let $F_{1}$ and $F_{2}$ be two mappings from $C \times C \rightarrow \mathbb{R}$ satisfying (A1)-(A4) and let $S_{1, \lambda}$ and $S_{2, \mu}$ be defined as in Lemma 2.7 associated to $F_{1}$ and $F_{2}$, respectively. For given $x^{*}, y^{*} \in C,\left(x^{*}, y^{*}\right)$ is a solution of problem (1.6) if and only if $x^{*}$ is a fixed point of the mapping $G: C \rightarrow C$ defined by

$$
G(x)=S_{1, \lambda}\left(S_{2, \mu} x\right), \forall x \in C,
$$

where $y^{*}=S_{2, \mu} x^{*}$.

Proof. By a similar argument as in the proof of Proposition 2.1 in [16], we have obtain the result.

We note from Lemma 2.7 that the mapping $G$ is nonexpansive. Moreover, if $C$ is a closed bounded convex subset of $H$, then the solution of problem (1.6) always exists. Throughout this paper, we denote the set of solutions of (1.6) and (1.7) by $\Omega$ and $\Omega_{1}$, respectively.

\section{Main result}

In this section, we prove weak and strong convergence theorems for finding a common element of the set of fixed points of a nonexpansive mapping and the set of solutions of the system of mixed equilibrium problems. 
Theorem 3.1. Let $C$ be a closed convex subset of a real Hilbert space $H$. Let $F_{1}$ and $F_{2}$ be two bifunctions from $C \times C \rightarrow \mathbb{R}$ satisfying (A1)-(A4). Let $\lambda, \mu>0$ and let $S_{1, \lambda}$ and $S_{2, \mu}$ be defined as in Lemma 2.7 associated to $F_{1}$ and $F_{2}$, respectively. Let $T$ be a nonexpansive mapping of $C$ into itself such that $F(T) \cap \Omega \neq \emptyset$. Suppose $x_{0}=x \in C$ and $\left\{x_{n}\right\},\left\{y_{n}\right\},\left\{z_{n}\right\}$ are given by

$$
\begin{cases}z_{n} \in C ; F_{2}\left(z_{n}, z\right)+\varphi(z)-\varphi\left(z_{n}\right)+\frac{1}{\mu}\left\langle z-z_{n}, z_{n}-x_{n}\right\rangle \geq 0, & \forall z \in C, \\ y_{n} \in C ; F_{1}\left(y_{n}, z\right)+\varphi(z)-\varphi\left(y_{n}\right)+\frac{1}{\lambda}\left\langle z-y_{n}, y_{n}-z_{n}\right\rangle \geq 0, & \forall z \in C, \\ x_{n+1}=\alpha_{n} x_{n}+\left(1-\alpha_{n}\right) T y_{n}, & \end{cases}
$$

for all $n \in \mathbb{N}$, where $\left\{\alpha_{n}\right\} \subset[a, b]$ for some $a, b \in(0,1)$. Then $\left\{x_{n}\right\}$ converges weakly to $\bar{x}=\lim _{n \rightarrow \infty} P_{F(T) \cap \Omega} x_{n}$ and $(\bar{x}, \bar{y})$ is a solution of problem (1.6), where $\bar{y}=S_{2, \mu} \bar{x}$.

Proof. Let $x^{*} \in F(T) \cap \Omega$. Then $x^{*}=T x^{*}$ and $x^{*}=S_{1, \lambda}\left(S_{2, \mu} x^{*}\right)$. Put $y^{*}=S_{2, \mu} x^{*}, y_{n}=S_{1, \lambda} z_{n}$ and $z_{n}=S_{2, \mu} x_{n}$. Since

$$
\begin{aligned}
\left\|y_{n}-x^{*}\right\| & =\left\|S_{1, \lambda} z_{n}-S_{1, \lambda} y^{*}\right\| \\
& \leq\left\|z_{n}-y^{*}\right\| \\
& =\left\|S_{2, \mu} x_{n}-S_{2, \mu} x^{*}\right\| \\
& \leq\left\|x_{n}-x^{*}\right\|,
\end{aligned}
$$

it follows by Lemma 2.1 that

$$
\begin{aligned}
& \left\|x_{n+1}-x^{*}\right\|^{2} \\
= & \left\|\alpha_{n} x_{n}+\left(1-\alpha_{n}\right) T y_{n}\right\|^{2} \\
= & \left\|\alpha_{n}\left(x_{n}-x^{*}\right)+\left(1-\alpha_{n}\right)\left(T y_{n}-x^{*}\right)\right\|^{2} \\
= & \alpha_{n}\left\|x_{n}-x^{*}\right\|^{2}+\left(1-\alpha_{n}\right)\left\|T y_{n}-x^{*}\right\|^{2}-\alpha_{n}\left(1-\alpha_{n}\right)\left\|T y_{n}-x_{n}\right\|^{2} \\
\leq & \alpha_{n}\left\|x_{n}-x^{*}\right\|^{2}+\left(1-\alpha_{n}\right)\left\|y_{n}-x^{*}\right\|^{2}-\alpha_{n}\left(1-\alpha_{n}\right)\left\|T y_{n}-x_{n}\right\|^{2} \\
\leq & \alpha_{n}\left\|x_{n}-x^{*}\right\|^{2}+\left(1-\alpha_{n}\right)\left\|x_{n}-x^{*}\right\|^{2}-\alpha_{n}\left(1-\alpha_{n}\right)\left\|T y_{n}-x_{n}\right\|^{2} \\
= & \left\|x_{n}-x^{*}\right\|^{2}-\alpha_{n}\left(1-\alpha_{n}\right)\left\|T y_{n}-x_{n}\right\| \\
\leq & \left\|x_{n}-x^{*}\right\|^{2} .
\end{aligned}
$$

Hence $\left\{\left\|x_{n+1}-x^{*}\right\|\right\}$ is a decreasing sequence and therefore $\lim _{n \rightarrow \infty}\left\|x_{n}-x^{*}\right\|$ exists. This implies that $\left\{x_{n}\right\},\left\{y_{n}\right\},\left\{z_{n}\right\}$ and $\left\{T y_{n}\right\}$ are bounded. From (3.2), we note that

$$
\alpha_{n}\left(1-\alpha_{n}\right)\left\|T y_{n}-x_{n}\right\| \leq\left\|x_{n}-x^{*}\right\|^{2}-\left\|x_{n+1}-x^{*}\right\|^{2} .
$$

Since $0<a \leq \alpha_{n} \leq b<1$ and $\lim _{n \rightarrow \infty}\left\|x_{n}-x^{*}\right\|^{2}=\lim _{n \rightarrow \infty}\left\|x_{n+1}-x^{*}\right\|^{2}$, we have

$$
a(1-b)\left\|T y_{n}-x_{n}\right\| \leq\left\|x_{n}-x^{*}\right\|^{2}-\left\|x_{n+1}-x^{*}\right\|^{2} \rightarrow 0
$$


This implies that $\lim _{n \rightarrow \infty}\left\|T y_{n}-x_{n}\right\|=0$. Since $S_{1, \lambda}$ and $S_{2, \mu}$ are firmly nonexpansive, it follows that

$$
\begin{aligned}
\left\|z_{n}-y^{*}\right\|^{2} & =\left\|S_{2, \mu} x_{n}-S_{2, \mu} x^{*}\right\|^{2} \\
& \leq\left\langle S_{2, \mu} x_{n}-S_{2, \mu} x^{*}, x_{n}-x^{*}\right\rangle \\
& =\frac{1}{2}\left(\left\|z_{n}-y^{*}\right\|^{2}+\left\|x_{n}-x^{*}\right\|^{2}-\left\|z_{n}-y^{*}-x_{n}+x^{*}\right\|^{2}\right),
\end{aligned}
$$

and so $\left\|z_{n}-y^{*}\right\|^{2} \leq\left\|x_{n}-x^{*}\right\|^{2}-\left\|z_{n}-x_{n}+x^{*}-y^{*}\right\|^{2}$. By the convexity of $\|\cdot\|^{2}$, we have

$$
\begin{aligned}
\left\|x_{n+1}-x^{*}\right\|^{2} & =\left\|\alpha_{n} x_{n}+\left(1-\alpha_{n}\right) T y_{n}\right\|^{2} \\
& =\left\|\alpha_{n}\left(x_{n}-x^{*}\right)+\left(1-\alpha_{n}\right)\left(T y_{n}-x^{*}\right)\right\|^{2} \\
& \leq \alpha_{n}\left\|x_{n}-x^{*}\right\|^{2}+\left(1-\alpha_{n}\right)\left\|T y_{n}-x^{*}\right\|^{2} \\
& \leq \alpha_{n}\left\|x_{n}-x^{*}\right\|^{2}+\left(1-\alpha_{n}\right)\left\|y_{n}-x^{*}\right\|^{2} \\
& \leq \alpha_{n}\left\|x_{n}-x^{*}\right\|^{2}+\left(1-\alpha_{n}\right)\left\|z_{n}-y^{*}\right\|^{2} \\
& \leq \alpha_{n}\left\|x_{n}-x^{*}\right\|^{2}+\left(1-\alpha_{n}\right)\left[\left\|x_{n}-x^{*}\right\|^{2}-\left\|z_{n}-x_{n}+x^{*}-y^{*}\right\|^{2}\right] .
\end{aligned}
$$

This implies that

$$
\left(1-\alpha_{n}\right)\left\|z_{n}-x_{n}+x^{*}-y^{*}\right\|^{2} \leq\left\|x_{n}-x^{*}\right\|^{2}-\left\|x_{n+1}-x^{*}\right\|^{2} .
$$

Since $0<a \leq \alpha_{n} \leq b<1$ and $\lim _{n \rightarrow \infty}\left\|x_{n}-x^{*}\right\|^{2}=\lim _{n \rightarrow \infty}\left\|x_{n+1}-x^{*}\right\|^{2}$, we obtain $\lim _{n \rightarrow \infty}\left\|z_{n}-x_{n}+x^{*}-y^{*}\right\|=0$. Similarly, we note that

$$
\begin{aligned}
\left\|y_{n}-x^{*}\right\|^{2} & =\left\|S_{1, \lambda} z_{n}-S_{1, \lambda} y^{*}\right\|^{2} \\
& \leq\left\langle S_{1, \lambda} z_{n}-S_{1, \lambda} y^{*}, z_{n}-y^{*}\right\rangle \\
& =\frac{1}{2}\left(\left\|y_{n}-x^{*}\right\|^{2}+\left\|z_{n}-y^{*}\right\|^{2}-\left\|y_{n}-x^{*}-z_{n}+y^{*}\right\|^{2}\right) \\
& \leq \frac{1}{2}\left(\left\|y_{n}-x^{*}\right\|^{2}+\left\|x_{n}-x^{*}\right\|^{2}-\left\|y_{n}-z_{n}-x^{*}+y^{*}\right\|^{2}\right),
\end{aligned}
$$

and so $\left\|y_{n}-x^{*}\right\|^{2} \leq\left\|x_{n}-x^{*}\right\|^{2}-\left\|y_{n}-z_{n}-x^{*}+y^{*}\right\|^{2}$. Thus, we have $\left\|x_{n+1}-x^{*}\right\|^{2} \leq \alpha_{n}\left\|x_{n}-x^{*}\right\|^{2}+\left(1-\alpha_{n}\right)\left\|y_{n}-x^{*}\right\|^{2}$

$$
\leq \alpha_{n}\left\|x_{n}-x^{*}\right\|^{2}+\left(1-\alpha_{n}\right)\left[\left\|x_{n}-x^{*}\right\|^{2}-\left\|y_{n}-z_{n}-x^{*}+y^{*}\right\|^{2}\right]
$$

Hence

$$
\left(1-\alpha_{n}\right)\left\|y_{n}-z_{n}-x^{*}+y^{*}\right\|^{2} \leq\left\|x_{n}-x^{*}\right\|^{2}-\left\|x_{n+1}-x^{*}\right\|^{2} .
$$

Since $0<a \leq \alpha_{n} \leq b<1$ and $\lim _{n \rightarrow \infty}\left\|x_{n}-x^{*}\right\|^{2}=\lim _{n \rightarrow \infty}\left\|x_{n+1}-x^{*}\right\|^{2}$, it follows that $\lim _{n \rightarrow \infty}\left\|y_{n}-z_{n}-x^{*}+y^{*}\right\|=0$. Hence

$\left\|T y_{n}-y_{n}\right\| \leq\left\|T y_{n}-x_{n}\right\|+\left\|x_{n}-z_{n}-x^{*}+y^{*}\right\|+\left\|z_{n}-y_{n}+x^{*}-y^{*}\right\| \rightarrow 0$, and therefore

$$
\left\|y_{n}-x_{n}\right\| \leq\left\|y_{n}-T y_{n}\right\|+\left\|T y_{n}-x_{n}\right\| \rightarrow 0
$$


Since

$$
\left\|T x_{n}-x_{n}\right\| \leq\left\|T x_{n}-T y_{n}\right\|+\left\|T y_{n}-x_{n}\right\| \leq\left\|x_{n}-y_{n}\right\|+\left\|T y_{n}-x_{n}\right\|,
$$

we get $\lim _{n \rightarrow \infty}\left\|T x_{n}-x_{n}\right\|=0$. Since $\left\{x_{n}\right\}$ is bounded, we assume that there exists a subsequence $\left\{x_{n_{i}}\right\}$ of $\left\{x_{n}\right\}$ such that $\left\{x_{n_{i}}\right\}$ converges weakly to $\bar{x}$. By Lemma 2.2, we have $\bar{x} \in F(T)$. Let $G$ be a mapping which defined as in Lemma 2.8. Thus, we have

$$
\left\|y_{n}-G\left(y_{n}\right)\right\|=\left\|S_{1, \lambda} S_{2, \mu} x_{n}-G\left(y_{n}\right)\right\|=\left\|G\left(x_{n}\right)-G\left(y_{n}\right)\right\| \leq\left\|x_{n}-y_{n}\right\|,
$$

and so

$\left\|x_{n}-G\left(x_{n}\right)\right\| \leq\left\|x_{n}-y_{n}\right\|+\left\|y_{n}-G\left(y_{n}\right)\right\|+\left\|G\left(y_{n}\right)-G\left(x_{n}\right)\right\| \leq 3\left\|x_{n}-y_{n}\right\| \rightarrow 0$.

By Lemma 2.2 and Lemma 2.8, we have $\bar{x} \in \Omega$ and hence $\bar{x} \in F(T) \cap \Omega$. Let $\left\{x_{n_{j}}\right\}$ be another sequence of $\left\{x_{n}\right\}$ such that $\left\{x_{n_{j}}\right\}$ converges weakly to $x$. We next show that $\bar{x}=\dot{x}$. Suppose that $\bar{x} \neq x$. By the Opial's condition, we get

$$
\begin{aligned}
\lim _{n \rightarrow \infty}\left\|x_{n}-\bar{x}\right\| & =\liminf _{i \rightarrow \infty}\left\|x_{n_{i}}-\bar{x}\right\|<\liminf _{i \rightarrow \infty}\left\|x_{n_{i}}-\dot{x}\right\|=\lim _{n \rightarrow \infty}\left\|x_{n}-\dot{x}\right\| \\
& =\liminf _{j \rightarrow \infty}\left\|x_{n_{j}}-\dot{x}\right\|<\liminf _{j \rightarrow \infty}\left\|x_{n_{j}}-\bar{x}\right\|=\lim _{n \rightarrow \infty}\left\|x_{n}-\bar{x}\right\| .
\end{aligned}
$$

This is a contradiction. Thus, we have $\bar{x}=\not x$. This implies that $\left\{x_{n}\right\}$ converges weakly to $\bar{x} \in F(T) \cap \Omega$. Put $u_{n}=P_{F(T) \cap \Omega} x_{n}$. Finally, we show that $\bar{x}=$ $\lim _{n \rightarrow \infty} u_{n}$. From $(2.1)$ and $\bar{x} \in F(T) \cap \Omega$, we have

$$
\left\langle\bar{x}-u_{n}, u_{n}-x_{n}\right\rangle \geq 0 .
$$

By Lemma 2.3, $\left\{u_{n}\right\}$ converges strongly to $\hat{x} \in F(T) \cap \Omega$ and hence

$$
\langle\bar{x}-\hat{x}, \hat{x}-\bar{x}\rangle \geq 0 \text {. }
$$

This conclude that $\bar{x}=\hat{x}$.

Setting $\mu=\lambda$ in Theorem 3.1, we have following result.

Corollary 3.2. Let $C$ be a closed convex subset of a real Hilbert space $H$. Let $F_{1}$ and $F_{2}$ be two bifunctions from $C \times C \rightarrow \mathbb{R}$ satisfying (A1)-(A4). Let $\lambda>0$ and let $S_{1, \lambda}$ and $S_{2, \lambda}$ be defined as in Lemma 2.7 associated to $F_{1}$ and $F_{2}$ respectively. Let $T$ be a nonexpansive mapping of $C$ into itself such that $F(T) \cap \Omega \neq \emptyset$. Suppose $x_{0}=x \in C$ and $\left\{x_{n}\right\},\left\{y_{n}\right\},\left\{z_{n}\right\}$ are given by

$$
\begin{cases}z_{n} \in C ; F_{2}\left(z_{n}, z\right)+\varphi(z)-\varphi\left(z_{n}\right)+\frac{1}{\lambda}\left\langle z-z_{n}, z_{n}-x_{n}\right\rangle \geq 0, & \forall z \in C, \\ y_{n} \in C ; F_{1}\left(y_{n}, z\right)+\varphi(z)-\varphi\left(y_{n}\right)+\frac{1}{\lambda}\left\langle z-y_{n}, y_{n}-z_{n}\right\rangle \geq 0, & \forall z \in C, \\ x_{n+1}=\alpha_{n} x_{n}+\left(1-\alpha_{n}\right) T y_{n}, & \end{cases}
$$

for all $n \in \mathbb{N}$, where $\left\{\alpha_{n}\right\} \subset[a, b]$ for some $a, b \in(0,1)$. Then $\left\{x_{n}\right\}$ converges weakly to $\bar{x}=\lim _{n \rightarrow \infty} P_{F(T) \cap \Omega} x_{n}$ and $(\bar{x}, \bar{y})$ is a solution of problem (1.7), where $\bar{y}=S_{2, \lambda} \bar{x}$.

Setting $\varphi=0$ in Theorem 3.1, we have following result. 
Corollary 3.3. Let $C$ be a closed convex subset of a real Hilbert space $H$. Let $F_{1}$ and $F_{2}$ be two bifunctions from $C \times C \rightarrow \mathbb{R}$ satisfying (A1)-(A4). Let $\lambda, \mu>0$ and let $T_{1, \lambda}$ and $T_{2, \mu}$ be defined as in Lemma 2.6 associated to $F_{1}$ and $F_{2}$, respectively. Let $S$ be a nonexpansive mapping of $C$ into itself such that $F(S) \cap \Omega_{1} \neq \emptyset$. Suppose $x_{0}=x \in C$ and $\left\{x_{n}\right\},\left\{y_{n}\right\},\left\{z_{n}\right\}$ are given by

$$
\left\{\begin{array}{l}
z_{n} \in C ; F_{2}\left(z_{n}, z\right)+\frac{1}{\mu}\left\langle z-z_{n}, z_{n}-x_{n}\right\rangle \geq 0, \quad \forall z \in C, \\
y_{n} \in C ; F_{1}\left(y_{n}, z\right)+\frac{1}{\lambda}\left\langle z-y_{n}, y_{n}-z_{n}\right\rangle \geq 0, \quad \forall z \in C, \\
x_{n+1}=\alpha_{n} x_{n}+\left(1-\alpha_{n}\right) S y_{n},
\end{array}\right.
$$

for all $n \in \mathbb{N}$, where $\left\{\alpha_{n}\right\} \subset[a, b]$ for some $a, b \in(0,1)$. Then $\left\{x_{n}\right\}$ converges weakly to $\bar{x}=\lim _{n \rightarrow \infty} P_{F(S) \cap \Omega_{1}} x_{n}$ and $(\bar{x}, \bar{y})$ is a solution of problem $(1.7)$, where $\bar{y}=T_{2, \mu} \bar{x}$.

Theorem 3.4. Let $C$ be a closed convex subset of a real Hilbert space $H$. Let $F_{1}$ and $F_{2}$ be two bifunctions from $C \times C \rightarrow \mathbb{R}$ satisfying (A1)-(A4). Let $\lambda, \mu>0$ and let $S_{1, \lambda}$ and $S_{2, \mu}$ be defined as in Lemma 2.7 associated to $F_{1}$ and $F_{2}$ respectively. Let $T$ be a nonexpansive mapping of $C$ into itself such that $F(T) \cap \Omega \neq \emptyset$. Suppose $x_{0}, u \in C$ and $\left\{x_{n}\right\},\left\{y_{n}\right\},\left\{z_{n}\right\}$ are given by

$$
\begin{cases}z_{n} \in C ; F_{2}\left(z_{n}, z\right)+\varphi(z)-\varphi\left(z_{n}\right)+\frac{1}{\mu}\left\langle z-z_{n}, z_{n}-x_{n}\right\rangle \geq 0, & \forall z \in C, \\ y_{n} \in C ; F_{1}\left(y_{n}, z\right)+\varphi(z)-\varphi\left(y_{n}\right)+\frac{1}{\lambda}\left\langle z-y_{n}, y_{n}-z_{n}\right\rangle \geq 0, & \forall z \in C, \\ x_{n+1}=\alpha_{n} u+\left(1-\alpha_{n}\right) T y_{n}, & \end{cases}
$$

for all $n \in \mathbb{N}$, where $\left\{\alpha_{n}\right\} \subset[0,1]$. If $\lim _{n \rightarrow \infty} \alpha_{n}=0, \sum_{n=1}^{\infty} \alpha_{n}=\infty$ and $\sum_{n=1}^{\infty}\left|\alpha_{n+1}-\alpha_{n}\right|<\infty$, then $\left\{x_{n}\right\}$ converges strongly to $\bar{x}=P_{F(T) \cap \Omega} u$ and $(\bar{x}, \bar{y})$ is a solution of problem (1.6), where $\bar{y}=S_{2, \mu} \bar{x}$.

Proof. Let $x^{*} \in F(T) \cap \Omega$. Then $x^{*}=T x^{*}$ and $x^{*}=S_{1, \lambda}\left(S_{2, \mu} x^{*}\right)$. Put $y^{*}=S_{2, \mu} x^{*}, y_{n}=S_{1, \lambda} z_{n}$ and $z_{n}=S_{2, \mu} x_{n}$. Thus, we have

$$
\begin{aligned}
\left\|x_{n+1}-x^{*}\right\| & =\left\|\alpha_{n} u+\left(1-\alpha_{n}\right) T y_{n}-x^{*}\right\| \\
& \leq \alpha_{n}\left\|u-x^{*}\right\|+\left(1-\alpha_{n}\right)\left\|y_{n}-x^{*}\right\| \\
& =\alpha_{n}\left\|u-x^{*}\right\|+\left(1-\alpha_{n}\right)\left\|S_{1, \lambda} z_{n}-S_{1, \lambda} y^{*}\right\| \\
& \leq \alpha_{n}\left\|u-x^{*}\right\|+\left(1-\alpha_{n}\right)\left\|z_{n}-y^{*}\right\| \\
& =\alpha_{n}\left\|u-x^{*}\right\|+\left(1-\alpha_{n}\right)\left\|S_{2, \mu} x_{n}-S_{2, \mu} x^{*}\right\| \\
& \leq \alpha_{n}\left\|u-x^{*}\right\|+\left(1-\alpha_{n}\right)\left\|x_{n}-x^{*}\right\| \\
& \leq \max \left\{\left\|u-x^{*}\right\|,\left\|x_{n}-x^{*}\right\|\right\} .
\end{aligned}
$$

By introduction, we obtain

$$
\left\|x_{n}-x^{*}\right\| \leq \max \left\{\left\|u-x^{*}\right\|,\left\|x_{0}-x^{*}\right\|\right\}
$$


for all $n \geq 1$. This implies that $\left\{x_{n}\right\}$ is bounded and hence the sequences $\left\{y_{n}\right\},\left\{z_{n}\right\}$ and $\left\{T y_{n}\right\}$ are also bounded. Moreover, we observe that

$$
\begin{aligned}
\left\|y_{n+1}-y_{n}\right\| & =\left\|S_{1, \lambda} z_{n+1}-S_{1, \lambda} z_{n}\right\| \leq\left\|z_{n+1}-z_{n}\right\| \\
& =\left\|S_{2, \mu} x_{n+1}-S_{2, \mu} x_{n}\right\| \leq\left\|x_{n+1}-x_{n}\right\|
\end{aligned}
$$

and

$$
\begin{aligned}
& \left\|x_{n+2}-x_{n+1}\right\| \\
= & \left\|\alpha_{n+1} u+\left(1-\alpha_{n+1}\right) T y_{n+1}-\alpha_{n} u-\left(1-\alpha_{n}\right) T y_{n}\right\| \\
= & \left\|\left(\alpha_{n+1}-\alpha_{n}\right) u+\left(1-\alpha_{n+1}\right)\left(T y_{n+1}-T y_{n}\right)+\left(\alpha_{n}-\alpha_{n+1}\right) T y_{n}\right\| \\
\leq & \left|\alpha_{n+1}-\alpha_{n}\right|\left(\|u\|+\left\|T y_{n}\right\|\right)+\left(1-\alpha_{n+1}\right)\left\|y_{n+1}-y_{n}\right\| \\
\leq & \left(1-\alpha_{n+1}\right)\left\|x_{n+1}-x_{n}\right\|+\left|\alpha_{n+1}-\alpha_{n}\right|\left(\|u\|+\left\|T y_{n}\right\|\right) .
\end{aligned}
$$

By Lemma 2.4, we obtain $\left\|x_{n+1}-x_{n}\right\| \rightarrow 0$ as $n \rightarrow \infty$.

Consequently, $\left\|y_{n+1}-y_{n}\right\| \rightarrow 0$ and $\left\|z_{n+1}-z_{n}\right\| \rightarrow 0$ as $n \rightarrow \infty$. Since

$$
x_{n+1}-x_{n}=\alpha_{n}\left(u-x_{n}\right)+\left(1-\alpha_{n}\right)\left(T y_{n}-x_{n}\right) \text {, }
$$

it follows from $\lim _{n \rightarrow \infty} \alpha_{n}=0$ and $\lim _{n \rightarrow \infty}\left\|x_{n+1}-x_{n}\right\|=0$ that

$$
\lim _{n \rightarrow \infty}\left\|T y_{n}-x_{n}\right\|=0 \text {. }
$$

As in the proof of Theorem 3.1, we obtain

$$
\left\|z_{n}-y^{*}\right\|^{2} \leq\left\|x_{n}-x^{*}\right\|^{2}-\left\|z_{n}-x_{n}+x^{*}-y^{*}\right\|^{2}
$$

and

$$
\left\|y_{n}-x^{*}\right\|^{2} \leq\left\|x_{n}-x^{*}\right\|^{2}-\left\|y_{n}-z_{n}-x^{*}+y^{*}\right\|^{2} .
$$

By the convexity of $\|\cdot\|^{2}$, we have

$$
\begin{aligned}
\left\|x_{n+1}-x^{*}\right\|^{2} & \leq \alpha_{n}\left\|u-x^{*}\right\|^{2}+\left(1-\alpha_{n}\right)\left\|y_{n}-x^{*}\right\|^{2} \\
& \leq \alpha_{n}\left\|u-x^{*}\right\|^{2}+\left(1-\alpha_{n}\right)\left\|z_{n}-y^{*}\right\|^{2} \\
& \leq \alpha_{n}\left\|u-x^{*}\right\|^{2}+\left(1-\alpha_{n}\right)\left[\left\|x_{n}-x^{*}\right\|^{2}-\left\|z_{n}-x_{n}+x^{*}-y^{*}\right\|^{2}\right]
\end{aligned}
$$

and

$$
\begin{aligned}
\left\|x_{n+1}-x^{*}\right\|^{2} & \leq \alpha_{n}\left\|u-x^{*}\right\|^{2}+\left(1-\alpha_{n}\right)\left\|y_{n}-x^{*}\right\|^{2} \\
& \leq \alpha_{n}\left\|u-x^{*}\right\|^{2}+\left(1-\alpha_{n}\right)\left[\left\|x_{n}-x^{*}\right\|^{2}-\left\|y_{n}-z_{n}-x^{*}+y^{*}\right\|^{2}\right] .
\end{aligned}
$$

This implies that

$$
\begin{aligned}
& \left(1-\alpha_{n}\right)\left\|z_{n}-x_{n}+x^{*}-y^{*}\right\|^{2} \\
\leq & \alpha_{n}\left\|u-x^{*}\right\|^{2}+\left\|x_{n}-x^{*}\right\|^{2}-\left\|x_{n+1}-x^{*}\right\|^{2} \\
\leq & \alpha_{n}\left\|u-x^{*}\right\|^{2}+\left\|x_{n}-x_{n+1}\right\|\left(\left\|x_{n}-x^{*}\right\|-\left\|x_{n+1}-x^{*}\right\|\right)
\end{aligned}
$$

and

$$
\begin{aligned}
& \left(1-\alpha_{n}\right)\left\|y_{n}-z_{n}-x^{*}+y^{*}\right\|^{2} \\
\leq & \alpha_{n}\left\|u-x^{*}\right\|^{2}+\left\|x_{n}-x^{*}\right\|^{2}-\left\|x_{n+1}-x^{*}\right\|^{2}
\end{aligned}
$$




$$
\leq \alpha_{n}\left\|u-x^{*}\right\|^{2}+\left\|x_{n}-x_{n+1}\right\|\left(\left\|x_{n}-x^{*}\right\|-\left\|x_{n+1}-x^{*}\right\|\right) .
$$

Since $\lim _{n \rightarrow \infty} \alpha_{n}=0$ and $\lim _{n \rightarrow \infty}\left\|x_{n+1}-x_{n}\right\|=0$, it follows that

$$
\lim _{n \rightarrow \infty}\left\|z_{n}-x_{n}+x^{*}-y^{*}\right\|=0 \text { and } \lim _{n \rightarrow \infty}\left\|y_{n}-z_{n}-x^{*}+y^{*}\right\|=0 .
$$

Hence

$$
\left\|T y_{n}-y_{n}\right\| \leq\left\|T y_{n}-x_{n}\right\|+\left\|x_{n}-z_{n}-x^{*}+y^{*}\right\|+\left\|z_{n}-y_{n}+x^{*}-y^{*}\right\| \rightarrow 0
$$

and therefore

$$
\left\|y_{n}-x_{n}\right\| \leq\left\|y_{n}-T y_{n}\right\|+\left\|T y_{n}-x_{n}\right\| \rightarrow 0
$$

Next, we show that

$$
\limsup _{n \rightarrow \infty}\left\langle u-\bar{x}, x_{n}-\bar{x}\right\rangle \leq 0,
$$

where $\bar{x}=P_{F(T) \cap \Omega} u$. To show this inequality, we choose a subsequence $\left\{y_{n_{i}}\right\}$ of $\left\{y_{n}\right\}$ such that

$$
\limsup _{n \rightarrow \infty}\left\langle u-\bar{x}, T y_{n}-\bar{x}\right\rangle=\lim _{i \rightarrow \infty}\left\langle u-\bar{x}, T y_{n_{i}}-\bar{x}\right\rangle .
$$

Since $\left\{y_{n_{i}}\right\}$ is bounded, there exists a subsequence $\left\{y_{n_{i_{j}}}\right\}$ of $\left\{y_{n_{i}}\right\}$ which converges weakly to $z$. Without loss of generality, we can assume that $y_{n_{i}} \rightarrow z$. From $\left\|T y_{n}-y_{n}\right\| \rightarrow 0$, we obtain $T y_{n_{i}} \rightarrow z$. By Lemma 2.2, we have $z \in F(T)$. Let $G$ be a mapping which defined in Lemma 2.8. Thus, we have

$\left\|y_{n}-G\left(y_{n}\right)\right\|=\left\|S_{1, \lambda} S_{2, \mu} x_{n}-G\left(y_{n}\right)\right\|=\left\|G\left(x_{n}\right)-G\left(y_{n}\right)\right\| \leq\left\|x_{n}-y_{n}\right\| \rightarrow 0$.

According to Lemma 2.2 and Lemma 2.8, we have $z \in \Omega$ and hence $z \in$ $F(T) \cap \Omega$. Now from $\bar{x}=P_{F(T) \cap \Omega} u$, we have

$$
\begin{aligned}
\limsup _{n \rightarrow \infty}\left\langle u-\bar{x}, x_{n}-\bar{x}\right\rangle & =\limsup _{n \rightarrow \infty}\left\langle u-\bar{x}, T y_{n}-\bar{x}\right\rangle \\
& =\lim _{i \rightarrow \infty}\left\langle u-\bar{x}, T y_{n_{i}}-\bar{x}\right\rangle \\
& =\langle u-\bar{x}, z-\bar{x}\rangle \leq 0 .
\end{aligned}
$$

Finally, we note that

$$
\begin{aligned}
& \left\|x_{n+1}-\bar{x}\right\|^{2} \\
= & \left\langle\alpha_{n} u+\left(1-\alpha_{n}\right) T y_{n}-\bar{x}, x_{n+1}-\bar{x}\right\rangle \\
= & \alpha_{n}\left\langle u-\bar{x}, x_{n+1}-\bar{x}\right\rangle+\left(1-\alpha_{n}\right)\left\langle T y_{n}-\bar{x}, x_{n+1}-\bar{x}\right\rangle \\
\leq & \alpha_{n}\left\langle u-\bar{x}, x_{n+1}-\bar{x}\right\rangle+\frac{1}{2}\left(1-\alpha_{n}\right)\left[\left\|T y_{n}-\bar{x}\right\|^{2}+\left\|x_{n+1}-\bar{x}\right\|^{2}\right] \\
\leq & \alpha_{n}\left\langle u-\bar{x}, x_{n+1}-\bar{x}\right\rangle+\frac{1}{2}\left(1-\alpha_{n}\right)\left\|y_{n}-\bar{x}\right\|^{2}+\frac{1}{2}\left(1-\alpha_{n}\right)\left\|x_{n+1}-\bar{x}\right\|^{2} \\
\leq & \alpha_{n}\left\langle u-\bar{x}, x_{n+1}-\bar{x}\right\rangle+\left(1-\alpha_{n}\right)\left\|x_{n}-\bar{x}\right\|^{2}+\frac{1}{2}\left\|x_{n+1}-\bar{x}\right\|^{2} \\
(3.8) \leq & \left(1-\alpha_{n}\right)\left\|x_{n}-\bar{x}\right\|^{2}+2 \alpha_{n}\left\langle u-\bar{x}, x_{n+1}-\bar{x}\right\rangle .
\end{aligned}
$$

It follows from (3.7), (3.8) and Lemma 2.4, that $x_{n} \rightarrow \bar{x}$. This completes the proof.

Setting $\mu=\lambda$ in Theorem 3.4, we have following result. 
Corollary 3.5. Let $C$ be a closed convex subset of a real Hilbert space $H$. Let $F_{1}, F_{2}$ be two bifunctions from $C \times C \rightarrow \mathbb{R}$ satisfying (A1)-(A4). Let $\lambda>0$ and let $S_{1, \lambda}, S_{2, \lambda}$ be defined as in Lemma 2.7 associated to $F_{1}, F_{2}$ respectively. Let $T$ be a nonexpansive mapping of $C$ into itself such that $F(T) \cap \Omega_{1} \neq \emptyset$. Suppose $x_{0}=x \in C$ and $\left\{x_{n}\right\},\left\{y_{n}\right\},\left\{z_{n}\right\}$ are given by

$$
\begin{cases}z_{n} \in C ; F_{2}\left(z_{n}, z\right)+\varphi(z)-\varphi\left(z_{n}\right)+\frac{1}{\lambda}\left\langle z-z_{n}, z_{n}-x_{n}\right\rangle \geq 0, & \forall z \in C, \\ y_{n} \in C ; F_{1}\left(y_{n}, z\right)+\varphi(z)-\varphi\left(y_{n}\right)+\frac{1}{\lambda}\left\langle z-y_{n}, y_{n}-z_{n}\right\rangle \geq 0, & \forall z \in C, \\ x_{n+1}=\alpha_{n} u+\left(1-\alpha_{n}\right) T y_{n}, & \end{cases}
$$

for all $n \in \mathbb{N}$, where $\left\{\alpha_{n}\right\} \subset[a, b]$ for some $a, b \in(0,1)$. Then $\left\{x_{n}\right\}$ converges strongly to $\bar{x}=\lim _{n \rightarrow \infty} P_{F(T) \cap \Omega} x_{n}$ and $(\bar{x}, \bar{y})$ is a solution of problem (1.7), where $\bar{y}=S_{2, \lambda} \bar{x}$.

Setting $\varphi=0$ in Theorem 3.4, we have following result.

Corollary 3.6. Let $C$ be a closed convex subset of a real Hilbert space $H$. Let $F_{1}$ and $F_{2}$ be two bifunctions from $C \times C \rightarrow \mathbb{R}$ satisfying (A1)-(A4). Let $\lambda, \mu>0$ and let $T_{1, \lambda}$ and $T_{2, \mu}$ be defined as in Lemma 2.6 associated to $F_{1}$ and $F_{2}$, respectively. Let $S$ be a nonexpansive mapping of $C$ into itself such that $F(S) \cap \Omega_{1} \neq \emptyset$. Suppose $x_{0}=x \in C$ and $\left\{x_{n}\right\},\left\{y_{n}\right\},\left\{z_{n}\right\}$ are given by

$$
\left\{\begin{array}{l}
z_{n} \in C ; F_{2}\left(z_{n}, z\right)+\frac{1}{\mu}\left\langle z-z_{n}, z_{n}-x_{n}\right\rangle \geq 0, \quad \forall z \in C, \\
y_{n} \in C ; F_{1}\left(y_{n}, z\right)+\frac{1}{\lambda}\left\langle z-y_{n}, y_{n}-z_{n}\right\rangle \geq 0, \quad \forall z \in C, \\
x_{n+1}=\alpha_{n} u+\left(1-\alpha_{n}\right) S y_{n},
\end{array}\right.
$$

for all $n \in \mathbb{N}$, where $\left\{\alpha_{n}\right\} \subset[a, b]$ for some $a, b \in(0,1)$. Then $\left\{x_{n}\right\}$ converges strongly to $\bar{x}=\lim _{n \rightarrow \infty} P_{F(S) \cap \Omega_{1}} x_{n}$ and $(\bar{x}, \bar{y})$ is a solution of problem (1.7), where $\bar{y}=T_{2, \mu} \bar{x}$.

Acknowledgement. The first author is thankful to the Thailand Research Fund for financial support under Grant BRG5280016. Moreover, the second author would like to thank the Office of the Higher Education Commission, Thailand for supporting by grant fund under Grant CHE-Ph.D-THA-SUP/86/2550, Thailand.

\section{References}

[1] F. Acker and M. A. Prestel, Convergence d'un schéma de minimisation alternée, Ann. Fac. Sci. Toulouse Math. (5) 2 (1980), no. 1, 1-9.

[2] R. P. Agarwal, Y. J. Cho, and N. Petrot, Systems of general nonlinear set-valued mixed variational inequalities problems in Hilbert spaces, Fixed Point Theory Appl. 2011 (2011):31, 10 pp; doi:10.1186/1687-1812-2011-31.

[3] E. Blum and W. Oettli, From optimization and variational inequalities to equilibrium problems, Math. Student 63 (1994), no. 1-4, 123-145.

[4] L. C. Ceng, C. Y. Wang, and J. C. Yao, Strong convergence theorems by a relaxed extragradient method for a general system of variational inequalities, Math. Methods Oper. Res. 67 (2008), no. 3, 375-390. 
[5] L. C. Ceng and J. C. Yao, A hybrid iterative scheme for mixed equilibrium problems and fixed point problems, J. Comput. Appl. Math. 214 (2008), no. 1, 186-201.

[6] Y. J. Cho, I. K. Argyros, and N. Petrot, Approximation methods for common solutions of generalized equilibrium, systems of nonlinear variational inequalities and fixed point problems, Comput. Math. Appl. 60 (2010), no. 8, 2292-2301.

[7] Y. J. Cho and N. Petrot, An optimization problem related to generalized equilibrium and fixed point problems with applications, Fixed Point Theory 11 (2010), no. 2, 237-250.

[8] _ On the system of nonlinear mixed implicit equilibrium problems in Hilbert spaces, J. Inequal. Appl. 2010 (2010), Article ID 437976, 12 pp.; doi:10.1155/ $2010 / 437976$

[9] Y. J. Cho, J. I. Kang, and X. Qin, Convergence theorems based on hybrid methods for generalized equilibrium problems and fixed point problems, Nonlinear Anal. 71 (2009), no. 9, 4203-4214.

[10] P. L. Combettes and S. A. Hirstoaga, Equilibrium programming in Hilbert spaces, J. Nonlinear Convex Anal. 6 (2005), no. 1, 117-136.

[11] S. D. Flåm and A. S. Antipin, Equilibrium programming using proximal-like algorithms, Math. Programming 78 (1997), no. 1, 29-41.

[12] K. Goebel and W. A. Kirk, Topics in Metric Fixed Point Theory, Cambridge Stud. Adv. Math., vol. 28, Cambridge Univ. Press, 1990.

[13] H. He, S. Liu, and Y. J. Cho, An explicit method for systems of equilibrium problems and fixed points of infinite family of nonexpansive mappings, J. Comput. Appl. Math. 235 (2011), no. 14, 4128-4139.

[14] M. R. Mann, Mean value methods in iteration, Proc. Amer. Math. Soc. 4 (1953), 506510 .

[15] A. Moudafi, Weak convergence theorems for nonexpansive mappings and equilibrium problems, J. Nonlinear Convex Anal. 9 (2008), no. 1, 37-43.

[16] A. Moudafi, From alternating minimization algorithms and system of variational inequalities to equilibrium problems, Comm. Appl. Nonlinear Anal. 16 (2009), no. 3, 3135 .

[17] Z. Opial, Weak convergence of the sequence of successive approximations for nonexpansive mappings, Bull. Amer. Math. Soc. 73 (1967), 595-597.

[18] M. O. Osilike and D. I. Igbokwe, Weak and strong convergence theorems for fixed points of pseudocontractions and solutions of monotone type operator equations, Comput. Math. Appl. 40 (2000), no. 4-5, 559-567.

[19] J.-W. Peng and J.-C. Yao, A new hybrid-extragradient method for generalized mixed equilibrium problems, fixed point problems and variational inequality problems, Taiwanese J. Math. 12 (2008), no. 6, 1401-1432.

[20] S. Plubtieng and K. Sombut, Weak convergence theorems for a system of mixed equilibrium problems and nonspreading mappings in a Hilbert space, J. Inequal. Appl. 2010 (2010), Art. ID 246237, 12 pp.

[21] S. Plubtieng and T. Thammathiwat, A viscosity approximation method for equilibrium problems, fixed point problems of nonexpansive mappings and a general system of variational inequalities, J. Global Optim. 46 (2010), no. 3, 447-464.

[22] X. Qin, S. S. Chang, and Y. J. Cho, Iterative methods for generalized equilibrium problems and fixed point problems with applications, Nonlinear Anal. Real World Appl. 11 (2010), no. 4, 2963-2972.

[23] R. T. Rockafellar, Monotone operators and the proximal point algorithm, SIAM J. Control Optim. 14 (1976), no. 5, 877-898.

[24] W. Takahashi, Nonlinear Functional Analysis, Yokohama Publishers, Yokohama, 2000.

[25] Introduction to Nonlinear and Convex Analysis, Yokohama Publishers, Yokohama, 2009. 
[26] W. Takahashi and M. Toyoda, Weak convergence theorems for nonexpansive mappings and monotone mappings, J. Optim. Theory Appl. 118 (2003), no. 2, 417-428.

[27] S. Takahashi and W. Takahashi, Viscosity approximation methods for equilibrium problems and fixed point problems in Hilbert spaces, J. Math. Anal. Appl. 331 (2007), no. $1,506-515$.

[28] R. U. Verma, Projection methods, algorithms, and a new system of nonlinear variational inequalities, Comput. Math. Appl. 41 (2001), no. 7-8, 1025-1031.

[29] H. K. Xu, Viscosity approximation methods for nonexpansive mappings, J. Math. Anal. Appl. 298 (2004), no. 1, 279-291.

[30] Y. Yao, Y. C. Liou, and J. C. Yao, A new hybrid Iterative algorithm for fixed point problems, variational inequality problems, and mixed equilibrium problems, Fixed Point Theory Appl. 2008 (2008), Art. ID 417089, 15 pp.; doi:10.1155/2008/417089.

[31] Y. Yao, Y. J. Cho, and Y. C. Liou, Iterative algorithms for variational inclusions, mixed equilibrium and fixed point problems with application to optimization problems, Cent. Eur. J. Math. 9 (2011), no. 3, 640-656.

[32] — Algorithms of common solutions for variational inclusions, mixed equilibrium problems and fixed point problems, European J. Oper. Res. 212 (2011), no. 2, 242-250.

Somyot Plubtieng

Department of Mathematics

FACULTY OF SCIENCE

NARESUAN UNIVERSITY

Phitsanulok 65000, Thailand

E-mail address: Somyotp@nu.ac.th

KAMONRAT SOMBUT

Department of Mathematics

FaCUlty of SCIENCE

Naresuan University

PhitsanuloK 65000, Thailand

E-mail address: jee_math46@hotmail.com 